\title{
Use of acute anti-migraine medication and risk of development of chronic headache: a prospective population based study
}

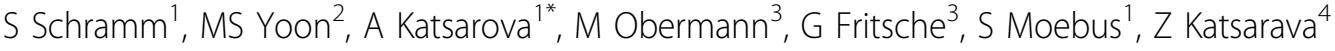 \\ From The European Headache and Migraine Trust International Congress \\ London, UK. 20-23 September 2012
}

\section{Introduction}

Overuse of acute pain medication is a risk factor for developing chronic headache.

\section{Objectives}

To investigate the association between the use of acute anti-migraine medication as single analgesics (SA), combination analgesics $(\mathrm{CA})$ and triptanes $(\mathrm{T})$ and the risk for chronic headache in patients with episodic migraine.

\section{Methods}

We used data of the German Headache Consortium (GHC) Study which is a population-based sample of 18,000 participants aged 18 to 65 years. Information about headache features, frequency, use of medication and years of education were collected at baseline (20032005) and follow up one (t1) and two (t2) years after baseline using mailed questionnaires. Participants with prophylactic headache or other prophylactic pain medication were excluded $(n=209)$. Primary outcome was defined as incidence of chronic headache (any headache on $\geq 15$ days/month) at $\mathrm{t} 1$ or $\mathrm{t} 2$ in participants with episodic migraine ( $\leq 14$ days of migraine/month) at baseline. We estimated odds ratios (OR) and 95\%-confidence intervals (95\%-CI), adjusting for headache days at baseline (interval scaled), education, age (interval scaled), gender and BMI classes (normal, overweight, obese).

\section{Results}

Of 18,000 people $9,944(55.2 \%)$ responded at baseline, of those 6,688 (67.3\%) resp. 6,975 (70.1\%) responded at t1 resp. t2. At baseline 1,601 participants had episodic

${ }^{1}$ Institute of Medical Informatics, Biometry and Epidemiology, University Duisburg-Essen, Germany

Full list of author information is available at the end of the article migraine. The incidence of chronicity was $6.2 \%$. Use of anti-migraine medication had a protective effect compared to no intake (SA: OR=0.39, 95\%-CI=0.19-0.78; CA: $0.60,0.22-1.61$; $\mathrm{T}: 0.34,0.10-1.15)$. This effect was stronger for $\mathrm{SA}$ than for $\mathrm{CA}(\mathrm{OR}=0.65,95 \%-\mathrm{CI}=0.28$ 1.50). Adjusting for age, gender and BMI classes did not notably change these results.

\section{Conclusion}

Our data indicate that use of acute anti-migraine medication irrespective of the type (SA, CA, T) reduces the risk for developing chronic headache.

\section{Conflict of interest}

Z. Katsarava received speaker honoraria and/or travel reimbursement from Allergan, Merck Serono, Bayer Shering, Biogen, St Jude Medical and served as consultant to Allergan.

\section{Author details \\ ${ }^{1}$ Institute of Medical Informatics, Biometry and Epidemiology, University Duisburg-Essen, Germany. ${ }^{2}$ Department of Neurology, Ruhr-University Bochum, Germany. ${ }^{3}$ Department of Neurology and Headache Center, University Duisburg-Essen, Germany. ${ }^{4}$ Department of Neurology, Evangelisches Krankenhaus Unna, Germany.}

Published: 21 February 2013

Reference

1. $\mathrm{ICH}-2$ : The International Classification of Headache Disorders. Cephalgia, 2 2004, 24:9-160.

doi:10.1186/1129-2377-14-S1-P164

Cite this article as: Schramm et al:: Use of acute anti-migraine medication and risk of development of chronic headache: a prospective population based study. The Journal of Headache and Pain 2013 14(Suppl 1):P164.

\section{SpringerOpen ${ }^{\circ}$}

(C) 2013 Schramm et al; licensee Springer. This is an Open Access article distributed under the terms of the Creative Commons Attribution License (http://creativecommons.org/licenses/by/2.0), which permits unrestricted use, distribution, and reproduction in any medium, provided the original work is properly cited. 